\title{
Ethics in scientific communication: study of a problem case
}

\author{
Robert L Berger Harvard Medical School, USA
}

\section{Abstract}

The hypothermia experiments performed on humans during the Second World War at the German concentration camp in Dachau have been regarded as crimes against humanity, disguised as medical research. For almost 50 years, scientists maintained that the study produced valuable, even if not totally reliable, information. In recent years, the results from the Dachau hypothermia prcject were glamorized with life-saving potential and a heated ethical dialogue was activated about the use of life-saving but tainted scientific information. In the wake of the debate, an in-depth examination of the scientific rigour of the project was performed and revealed that neither the science nor the scientists from Dachau could be trusted and that the data were worthless. The body of medical opinion accepted the unfavourable determination but a few scientists and ethicists have continued to endorse the validity, of at least parts, of the Dachau hypothermia data.

The conduct of the scientific communications about the Dachau hypothermia experiments by the scientific and ethical communities invites serious consideration of a possible ethical misadventure. It appears that for almost 50 years, the results of the study had been endorsed without careful examination of the scientific base of the experiments and that secondary citation of relevant original material may have been commonly employed. These infractions contributed to a myth that good science was practised by the Nazis at Dachau. The more recent emphasis on the life-saving potential of the Dachau data, without citation of credible supporting evidence, has also been misleading. Similarly, acceptance of a determination by an in-depth examination that the 'whole' Dachau project is flawed with simultaneous endorsement of the validity of 'parts' of the results, poses an ethical problem.

It is advisable that before seeking ethical consultation about the use of unethically obtained data, scientists should examine the quality of science behind the controversial information and ethicists

\section{Key words}

Ethics in scientific communication; Dachau hypothermia experiments. should verify the integrity of the material prior to engaging in a dialogue.

Towards the end of the Second World War the allied armies came across an extensive network of barbaric medical experiments that had been conducted on humans by German physician investigators. One of these projects dealt with immersion hypothermia and was carried out at the Dachau concentration camp. The work was directed by Dr Sigmund Rascher, an air force (Luftwaffe) medical officer. According to available information approximately 300 male prisoners were forced into iced water baths during 400 experiments so that many of the men were cooled more than once (1). Postwar testimony indicates that 80 to 90 victims died during the freezing and attempted re-warming. Only a handful of those who survived the experiments lived to see the end of the war.

\section{Reception and reporting of the Dachau hypothermia experiments}

After conclusion of the hostilities, a US army neuropsychiatrist, Leo Alexander, was assigned to investigate the medical experiments performed on prisoners at the Dachau concentration camp. The records of most concentration camp medical studies on humans were destroyed by the Germans prior to capture of the camps by the allied forces. However, a 56-page scientific report about the Dachau human hypothermia experiments, submitted by Rascher to Heinrich Himmler (commander of the SS and in charge of the concentration camps), was found by a US army unit, hidden in a salt mine near Hallein, Austria along with Himmler's massive files. In 1946, Alexander submitted a 228-page report on the results of his extensive investigation. The document incorporated the complete Rascher to Himmler report and has since served as essentially the sole original source material about the Dachau hypothermia experiments (2).

Alexander concluded in his report, that even though the experiments 'wallowed in blood', the work produced useful information (2). However, in a 1949 article, Alexander changed his earlier 
assessment and revealed that some of the data from Dachau had proved fraudulent and the results of the study could not be trusted (3). Similarly, at the Nuremberg trials of major medical war criminals, both the prosecution and Dr Andrew Ivy, a representative of the American Medical Association, maintained that the concentration camp human experiments were of no medical value (4). Moreover, scattered comments appeared in the medical literature about the unreliability of the Dachau data (5).

Despite the scepticism expressed about the integrity of the Dachau results, scientists in Canada, the United States and Great Britain have referred to the study repeatedly. Moe noted that by 1984 more than 45 scientific articles had cited the Dachau hypothermia experiments (5). Frequent citation of the data from Dachau in reputable medical journals eventually helped create an impression that, in spite of the deplorable inhumane methods, the work was scientifically correct. In the late 1980 s, Robert Pozos, a hypothermia physiologist, turned to the media and to the ethical community with his concern about using tainted data from Dachau. He acknowledged that the methods of the Dachau experiments were unethical but also expressed confidence in the scientific integrity of the study and maintained that the use of the results could advance hypothermia research and improve on available treatment of hypothermia victims, with the potential of saving lives $(6,7)$.

A public debate ensued. Both the ethicists and the media embraced the debate and dramatized the issue as a moral dilemma about saving lives by using data obtained through unethical experiments. The controversy was heated and intense $(7,8,9)$. Along with the promise of advancing science, the lifesaving potential of the data was heavily emphasized but never in my view convincingly documented $(8,9)$. Two critical premises about the data produced by the Nazis in Dachau were apparently taken for granted and rarely discussed by the participants in the recent dialogue. First, it was assumed that the results from the hypothermia experiments were scientifically sound and secondly, the claim was accepted that the data had the potential of advancing medical science and of saving lives. In spite of the gross ethical violations and the doubts expressed about the scientific integrity of the study, the reliability of the data had not been investigated $(8,9)$. Moreover, the probability that the data from Dachau had become obsolete with the passage of almost a half of a century, had not been entertained. The major advances in knowledge about hypothermia during the last 50 years, accomplished through highly sophisticated technology, should have raised serious questions about the likelihood that work performed with the relatively primitive methods of the early nineteen-forties could contribute appreciably to the prevailing state of the art. Thus, in spite of cogent reasons for scepticism about the quality or value of the Nazi hypothermia data, the reliability of the work that produced the information was not examined.

Some scientists defended the use of the Dachau data on the grounds that similar information would not be available from other sources, as the inhumane experimentation performed in the concentration camps had been unprecedented and in all likelihood would not be repeated $(7,10)$. These investigators acknowledged that the science produced in Dachau was flawed and that the chief investigator's credibility was severely compromised but they also insisted that selected results should be regarded as valid because they were consistent with observations published by other reputable scientists $(5,7,11)$. It was further argued that no conclusive evidence had been presented to show that the data were defective and therefore there was no reason to reject the information. A detailed endorsement of the scientific health of the Dachau hypothermia experiments was issued by Robert Pozos in 1989, through a recorded formal lecture (7).

\section{Re-evaluation and the response}

Because of lingering doubts about the scientifig validity of the Dachau data and my scepticism abou the probability that such relatively obsolete information could be useful, I embarked on thorough examination of the scientific quality of the Dachau hypothermia experiments. In this effort, I studied the Alexander report, reviewed his collected papers and the scientific literature about hypothermia, relied on the knowledge gained from my experience with cooling several thousand patients for heart surgery, and examined available documents about medical experiments in Nazi concentration camps (12). To my surprise, access to the Alexander report proved most difficult. The volume was not available in any of Boston's several medical libraries and only two copies circulated through the nationwide interlibrary loan system. Parts of Alexander's report were also published in the more readily available volumes entitled Trials of War Criminals before the Nuremberg Military Tribunals but this source offers only an incomplete reproduction and has rarely been cited in the medical literature (1). The difficult access to the Alexander report combined with the undeserved favourable reception of the Dachau hypothermia data, raised the suspicion that not all who cited Alexander's work had read the original text but had obtained the information from descriptions of the document by others and then resorted to secondary citation by listing the original Alexander title as the reference instead of the actual source they perused.

The in-depth examination of the available information revealed that the Dachau experiments were conducted without an organized experimental 
protocol, the methods of study were flawed and execution of the work was haphazard. Some of the alleged observations were either falsified or fabricated and the reported results showed internal inconsistencies. Conclusions were frequently not justified by the data presented. The project's chief investigator, Sigmund Rascher, was not a qualified scientist and lacked the integrity to conduct an acceptable scientific inquiry. His shortcomings as an investigator were recognized by his colleagues and superiors. In order to lend credibility to the Dachau hypothermia enterprise, Himmler recruited two competent scientists. However, the two men served essentially as part-time consultants and did not have the power or the will to control the administrative or scientific aspects of the study. Both advisers abandoned the project after the first 50 experiments and did not participate in the remaining 350 studies. Available documents also revealed that Rascher's other investigative efforts were motivated by greed for power and material gain, evidenced gross incompetence and produced a brand of pseudoscience that featured torture and murder. Eventually Rascher lost the trust of his Nazi mentors. He was arrested, charged with a variety of crimes, including scientific fraud, and was executed, presumably on the orders of his Nazi protector, Heinrich Himmler. In brief, the examination of the available information revealed that neither the science nor the scientist from Dachau could be trusted and the data produced were not reliable or usable.

\section{Scores of letters}

The results of my analysis of the Dachau hypothermia experiments were published in the New England fournal of Medicine after the customary stringent peer review process (12). The reviewers accepted the conclusion that the 'science' emanating from Dachau was severely flawed. A companion editorial in the same issue of the journal noted that: 'This evidence is sufficient for Berger to show convincingly that the hypothermia experiments, in addition to being bestial, were poorly designed and sloppily conducted, and the results were contradictory and probably freely fabricated. In short, the hypothermia experiments were scientifically worthless' ... (13). Scores of letters to the editors addressed the ethical dilemma of using or publishing the Dachau data but none took issue with the determination that the science was unacceptable and the data unusable (14). In a position paper, authored by 17 physicians, The New York State Medical Society's Commission on Ethics agreed that the science produced by freezing innocent prisoners in the ice tanks of Dachau was not reliable (15). Robert Pozos, the physiologist who brought the issue about the use of the Dachau data to the attention of the media and of the ethicists, with the message that the science was reliable, was quoted as having said in a newspaper interview that 'after reading Berger's report' he regarded the scientific methods of the Dachau study as 'atrocious' (16). However, subsequently, a few scientists and seemingly a greater number of ethicists have continued to place limited reliance on the scientific base of the Dachau hypothermia project and have claimed that the results were in part sound and useful. In a recent publication, the bioethicist Jay Katz and the hypothermia physiologist Robert Pozos, acknowledged that the Dachau study 'as a whole' lacked scientific validity but insisted that parts are valid because individual findings are reported (from Dachau) that either confirmed prior experimental data or produced new data that scientists in the West have considered valid ...'. Katz and Pozos listed five items from the Dachau study they believed to be valid. Each of the five items was referenced separately to my article, where they are listed as samples of what I consider to be unreliable information from Dachau together with detailed reasons for the unfavourable judgement (17).

Another expression of continued partial support for the results produced in Dachau came in the form of a British Broadcasting Corporation television programme that explored the ethical dilemma of using the Dachau data (18). The BBC film featured, among others, a British navy hypothermia specialist who related that the scientific methods used in Dachau left a great deal to be desired and that Berger's paper represented 'a good critical analysis'. $\mathrm{He}$ added, however, that the available information is limited and not sufficient to pass an unfavourable judgement. He listed specific data from Dachau that he thought were valid and valuable, plainly regarding the available information as sufficient to validate selected data from the project. The narrator further argued that the results obtained in Dachau were instrumental in the conception of an ongoing project on protection against 'post-rescue collapse' from immersion hypothermia. The current work by the British navy, presumably based on specific information from Dachau, was illustrated through telegenic footage showing a helicopter rescuing a mock hypothermia victim from the ocean. The connection between the work from Dachau and the ongoing research by the British navy investigators seemed to me to be tentative.

\section{Cursory coverage}

During the half-hour BBC programme, only cursory coverage was given to the detailed documentation about the flaws in the scientific methods of the Dachau study. Three prominent ethicists discussed the dilemma about the use of the tainted data and conveyed a distinct impression that in their view the scientific information from Dachau was valid and that its use could save lives. Two concentration camp survivors and a rabbi, with an apparent 
conviction that the science from Dachau was sound, also voiced opinions about using the data. The body of medical opinion that the Dachau results were worthless, was hardly mentioned and then lost in the enthusiastic discussion about the use of tainted data with the potential of saving lives.

\section{Comments}

For nearly 50 years, scientists in the western world referred liberally to the Dachau hypothermia experiments, despite the widespread contempt for the cruelty employed in the conduct of the research and the repeated reservations expressed about the scientific integrity of the project. Surprisingly, the misgivings about the reliability of the results failed to trigger either a full examination of the quality of the work or greater circumspection about citing the study.

The initial misconceptions about the value of the Dachau study may have been fortified in recent years by scientists who in the process of seeking ethical guidance did not, in my view, give sufficient weight to the persistent doubts about the scientific integrity of the work $(6,7)$. Moreover, both scientists and ethicists ascribed to the Dachau data life-saving potential that permitted a dramatic formulation of the controversy in terms of a life-and-death issue, which added greatly to the appeal of the debate. Although the nature of the potentially life-saving data was never to my mind adequately identified, the dramatization intensified the pitch of the controversy. The topic became even more popular as the media joined in the fray. The conclusion, from my in-depth examination, that the science practised in Dachau was inferior, has been accepted by a broad mix of scientists, including peer reviewers, editors of a medical journal, physicians writing to these editors and a state medical society commission on biomedical ethics. It seemed logical that documentation of the scientific flaws in the Dachau experiments would dispel any misconception on the utility of the information and confirm the futility of the ethical debate concerning the use of the data. The logic behind acceptance of selected parts of the data from Dachau deserves further comment.

The proposition by endorsers of the Dachau data that the study 'as a whole' cannot be trusted but selected items are valid and can be used, contravenes, in my view, fundamental standards of the scientific process. The Dachau hypothermia experiments featured fraud and incompetence performed by an investigator who was a habitual liar, so that no part of the project can be trusted even if selected components happen to be in agreement with data produced by others. The flaws pervade the whole work and do not permit separation of the results into credible and non-credible categories any more than the truth can be discerned from the utterings of a habitual liar (19). The evidence mandates, in my opinion, rejection of the wholem project and does not allow exemption of individual $\overrightarrow{\overline{\overrightarrow{ }}}$. items. Usually an entire investigative effort is? condemned even if only one part is fraudulent. With the Dachau experiments, the entire project is? suspect.

Another suggestion that agreement between $\frac{\bar{\sigma}}{\bar{s}}$ selected items from the Dachau project and prior $\vec{\Phi}$ experimental results reported by others confirms the $\varrho$ reliability of the Nazi data is also untenable. The fallacy of this concept is readily illustrated by $\vec{O}$ Alexander's discovery that Rascher fabricated data freely about the time-frame of tolerance for $\vec{\omega}$ hypothermia in order to be consistent with previous? observations on German Air Force crews downed in the cold sea, and to keep his project relevant to thei goals set by his Nazi superiors (3). Thus, Rascher's. data on tolerance for immersion hypothermia are clearly fraudulent, but they are also consistent with $y$ previous observations by others. This example을 illustrates that resemblance of two pieces of information does not necessarily mean that both can be trusted.

Guidelines on communication between ethicists and scientists about the scientific aspects of ethical issues are imprecise, since firm rules have not been $\vec{\theta}$ enunciated. Ethicists tend to assume that scientifice issues brought to their attention for ethical consideration are based on sound science. Since th may not be always the case, it is most important that before requesting ethical opinion, scientists shouldo scrutinize the quality of science behind topics with\% dubious ethical origins, and transmit a frank ㅡำ assessment of their findings. Similarly, prior to $\overrightarrow{0}$ embarking on ethical deliberations about the use of 3 tainted data, ethicists have an obligation to verify the scientific integrity of a research effort with? questionable ethics and ensure that the information is usable. The mere initiation of an ethical dialogue. can promote untrustworthy products and the very conduct of the debate can bestow scientific endorsement. A combined effort by ethicists and을 scientists can identify unreliable information that does not warrant ethical discussion about its use. $\frac{\text { ? }}{5}$ The drama or the glamour of a topic should not blind one into an inappropriate dialogue.

\section{Holocaust revisionists}

Inferior science is usually rejected and not used by scientists. Ethicists are rarely consulted about the? use of non-usable data even if they were obtained by unethical means. Jay Katz, a prominent biomedical ethicist, noted that '.. it seems evident that the ethical problem of using data and benefiting from ${ }^{-}$ evil is moot, if they prove to be useless ...' (20). In view of the body of medical opinion that the Dachau hypothermia experiments did not produce usableo scientific information, the continued reliance even on parts of the data must be questioned. I am 
compelled to challenge the view that the pseudoscience practised in a Nazi concentration camp was genuine science and to debunk a misconception that the scientific quality of tainted data is irrelevant to ethical dialogues. The debate about the use of the Dachau hypothermia data has already created what I consider to be an erroneous favourable impression about the scientific quality of at least one flawed Nazi medical project, and has in my view helped to advance, perhaps unwittingly, the assertion by Holocaust revisionists that the medical experiments perpetrated in German concentration camps were justified since the results advanced science and medicine and thus, Hitler's madness benefited humanity.

Cessation of the debate about use of the data from Dachau, does not mean banning access to information about the Dachau hypothermia experiments or relegating the truth about the evils of Nazi science to oblivion. Human experimentation in the German concentration camps represents a chapter of shame in the history of medicine. Civilization cannot afford a second coming of Dachau and the lessons from the experience cannot be ignored by blotting from memory the horrors of Nazi science. The story about perversion of medical experimentation by German scientists needs to be recalled and recorded in the annals of medical research as an episode of infamy that featured torture, murder and almost complete genocide with the enthusiastic co-operation of individual Nazi doctors and the support of the German medical establishment. Instead of expending our energies on debating the ethical implications of the use of the useless, we must dedicate our efforts to exploration of the genesis of these crimes perpetrated in the name of medicine and persist in our determination to prevent exploitation or violation of innocent victims in the name of medical science.

Robert L Berger, MD, is Associate Clinical Professor of Surgery, Harvard Medical School, Boston, USA.

\section{References}

(1) Freezing experiments. In: Trials of war criminals before the Nuremberg Military Tribunals [vol 1]: The medical case. Washington, DC: Government Printing Office, 1946-49: 198-260.
(2) Alexander L. The treatment of shock from prolonged exposure to cold, especially in water. Combined intelligence objectives subcommittee. Target no 24, report no 250. Washington, DC: Office of the Publication Board, Department of Commerce, 1946.

(3) Alexander L. Medical science under dictatorship. New England journal of medicine 1949; 241: 39-47.

(4) Mitscherlich A, Mielke F. Doctors of infamy: the story of the Nazi medical crimes. [Norden $\mathrm{H}$ trans.] New York: Henry Schuman, 1949.

(5) Moe K. Should the Nazi research data be cited? Hastings Center report 1984; 14, 6: 5-7.

(6) The MacNeil/Lehrer News Hour [TV programme]. New York and Washington. Corporation for Public Broadcasting. 1988 Aug 1.

(7) Pozos R S. Can scientists use information derived from concentration camps? In: Conference on the meaning of the Holocaust for bioethics. University of Minnesota, Minneapolis, 1989 May 17-19. Transcription of official recording, 1989: 1-17.

(8) The Holocaust and biomedical ethics. Conference on the meaning of the Holocaust for bioethics. University of Minnesota, Minneapolis, 1989 May 17-19.

(9) Caplan A L, ed. When medicine went mad. Totowa, NJ: Humana Press, 1992.

(10) Hegnauer A H. Lethal hypothermic temperatures for dog and man. Annals of the New York Academy of Science 1959; 80: 315-319.

(11) Pozos R S. Scientific inquiry and ethics. See reference (9): 108

(12) Berger R L. Nazi science - the Dachau hypothermia experiments. New England journal of medicine 1990; 322: 1435-1440.

(13) Angell M. The Nazi hypothermia experiments and unethical research today. New England journal of medicine 1990; 322: 1462-1464.

(14) Nazi science [letters to the Editor - several]. New England journal of medicine 1991 ; 324: 845-847.

(15) Rosner F, Bennett A J, Cassell EJ et al. The ethics of using scientific data obtained by immoral means. New York state journal of medicine 1991; 91: 54-59.

(16) Lutz D. Surgeon calls hypothermia research bad science. Minnesota daily 1990 May 17: 12.

(17) Katz J, Pozos R S. The Dachau hypothermia study an ethical and scientific commentary. See reference (9): 135-140.

(18) Nazi science [TV programme]. British Broadcasting Corporation. Antenna team. 1991.

(19) Berger R L. Nazi science. Comments on the validation of the Dachau hypothermia experiments. See reference (9): 109-134.

(20) Katz J. Abuse of human beings for the sake of science. See reference (9): 234-270. 